\title{
Chapter 17 \\ Hong Kong, China Employers' Perspectives on a Carbon-Constrained Economy and How Technical and Vocational Education and Training Should Respond
}

\author{
Rupert Maclean, Eric Tsang, and John Fien
}

\section{Introduction}

Climate change is generating economic and environmental dislocations that are set to increase in the years to come (IPCC 2007). This move will lead to significant changes required in adaptation and mitigation policies (Martinez-Fernandez et al. 2010). These changes in policy will also provide opportunities to those cities and regions that seek to address climate change by pursuing lower emission technologies. Their actions in doing so will see the reengineering of established production techniques and boost demand for climate-compatible goods and services. Those places that best anticipate and respond to these needs will be positioned for significant growth in the years ahead (Stern 2009). Various studies in the literature on the impact of Climate change and employment (e.g. MartinezFernandez et al. 2010) suggest that the impact of climate change on the global labour market is uncertain although indications are that there is an increasing emphasis on green growth in the business and industrial sector. As such, the labour market can benefit from an increasing demand for employees equipped with the

\footnotetext{
This research study has been largely funded to date by The Hong Kong Institute of Education. The authors would like to express their thanks to Will Douglas, Project Manager for the UNESCO Chair in TVET and Lifelong Learning, and to PhD Ms XIE Qing (Jenny), both in HKIEd, for their valuable contributions to this project.

R. Maclean ( $\square)$

Department of International Education and Lifelong Learning, The Hong Kong Institute of Education, 10 Lo Ping Road, Tai Po, Hong Kong, China

e-mail: maclean@ied.edu.hk

E. Tsang

Department of Science and Environmental Studies, The Hong Kong Institute of Education, 10 Lo Ping Road, Tai Po, Hong Kong, China

J. Fien

Sustainability, Design \& Social Context Office, RMIT University, Hamilton, VIC, Australia
} 
desired green skills (Fien et al. 2008). As there were no similar studies in Hong Kong, China, this article is a first attempt to address this issue.

The World Bank valued the global carbon market under the Kyoto Protocol's Clean Development Mechanism (CDM) at \$64 billion in 2007 and predicted that it would rise to $\$ 500$ billion by 2012 . In reality, it rose to a peak of $\$ 144$ billion in 2009 before dipping to $\$ 142$ billion in 2010, possibly due to uncertainty about market rules following the Kyoto Protocol's expiry in 2012. Clean technology has become the fastest growing sector in venture capital and private equity investment, with the top 10 banks in Hong Kong, China committing 10\%-15\% of project financing to renewable and clean technology (The Climate Group 2008). As a result, carbon emission reductions through energy-efficient transport, buildings, industrial equipment, renewable energy and waste reduction are creating both business opportunities and improved environmental outcomes. The long-term impact of the research reported herein will be enhanced prospects for economic prosperity and environmental sustainability in Hong Kong, China.

Hong Kong, China lacks natural resources and is heavily reliant on the service sector to provide employment opportunities, as the majority of manufacturing operations have relocated to mainland PRC. Manufacturing now employs less than $4 \%$ of the workforce, and traditional vocational skills are no longer required. The construction industry employs approximately $8 \%$ of the workforce, and the largest sector, encompassing wholesale/retail trade, catering, hotels and food services, employs approximately $32.6 \%$. Transport, storage and communications employ $12 \%$, finance and real estate employ $18 \%$ and government and social/ personal services employ $25 \%$ of the workforce.

As Hong Kong, China is a service-based city without energy-intensive manufacturing industries, its major contributors to greenhouse gases are power generation $(64 \%)$, transport $(16 \%)$, waste disposal $(9 \%)$, other energy sectors $(7 \%)$ and industrial processes (3\%) (Climate Change Business Forum 2009). The Chief Executive's 2010 Hong Kong Policy Address (Tsang 2010) stated that by 2020 the fuel for electricity generation would comprise $40 \%$ natural gas, $<10 \%$ coal, $3 \%-4 \%$ renewable energy and up to $50 \%$ imported nuclear fuel, using 2005 as the base. The switch to cleaner fuels is expected to reduce carbon intensity by $50 \%-60 \%$ and greenhouse gas emissions by up to $33 \%$. The actions necessary to achieve these targets include the control of emissions from electricity generation, regulation of transport emissions, significant reforms in supply chain management and logistics, adoption of emission reduction projects in the manufacturing sector, household and office energy conservation and the mandatory implementation of building energy codes.

In 2010, the Environment Bureau of the Government of the Hong Kong Special Administrative Region of the People's Republic of China issued a Climate Change Strategy and Action Agenda Consultation Document for Hong Kong (Environment Bureau/HKSAR Government [of the People's Republic of China] 2010), which identifies a number of key sectors as 'carbon-vulnerable', namely, electricity generation, property development, construction, transport and hospitality. These industries will inevitably face major changes as a result of carbon constraints and will thus 
require different skills from their technically and vocationally trained employees in future.

However, with such change comes opportunity, and the Environment Bureau/ HKSAR Government [of the People's Republic of China] (2010) has argued that 'going low-carbon' will 'generate opportunities in green and energy-efficient technologies and applications' as 'a promising new economic growth area in the coming decade'. Where environmental concerns were once associated with the problems of high costs and inefficiency, the climate crisis response is increasingly being associated with high-growth potential and increasingly attractive profits and returns.

As industries reengineer their resource and energy inputs, supply chain management, logistics, the design and construction of the built environment, production processes, services and water and waste management practices all require significant alterations to reduce carbon emissions. If these changes to economic practices are to be achievable and sustainable over the long-term, then the training of the general labour force must become a priority.

Currently, Hong Kong, China's technical and vocational education and training (TVET) sector requires that $5 \%$ of course content be related to environmental issues (Chan 2009). However, climate change and sustainable development constitute a small part of that content, and the specific competencies that students need to cater for economic, societal and environmental sustainability are not clearly delineated. The readiness of many teachers to take up these challenges may be compromised by commitments to prepare for other educational changes and the constant need to reinvent courses to suit industry requirements (Hung 1998). The TVET sector thus faces significant professional development challenges.

TVET has an important role to play in meeting the challenges of the new economy because of its close relationship with industry. As local industry adopts new international and industrial standards, vocational educators need swiftly and effectively to come to terms with this ongoing industrial reorientation. Industry also has an essential and pioneering role to play in influencing education for sustainability in ways that are embedded in the industrial reality of the local economy, which has major implications for economic and environmental sustainability and the local culture. Government success in reducing carbon emissions by $25 \%$ by 2030 will hinge not only on the cooperation of large companies but also on changes in the behaviour of the population as a whole, especially skilled workers.

To gain an initial insight into what employers perceived as key aspects of a greening economy, 15 representatives from potentially future carbon-constrained businesses were interviewed. Information was also sought from Hong Kong's Vocational Training Council (VTC) on 18 industries, with questions focusing on trade-specific environmental considerations in vocational training diploma programmes.

The findings of this preliminary qualitative study indicate a range of employer views, and it is hoped that further, more detailed studies will follow to support recommendations for changes in TVET policies for new and revised curricula, teaching packages, pedagogical approaches and campus operations. The ultimate goal is to enhance the skills and employability of Hong Kong, China's future workforce. 


\section{Research Methodology}

The purpose of this initial study is to collect information that will be used as input to the development of the rest of the study. This involves the identification of opportunities for industries in Hong Kong, China's to respond to a carbonconstrained future. Industry statistics and reports were analysed to identify carbon-vulnerable industries in Hong Kong, China's as well as those where there may be economic opportunities emerging for new industries or commercial activities from climate change. Interviews are being conducted (November 2010) with key representatives in these sectors, and NGOs, to identify (1) the occupations where new or reengineered jobs are being created (or need to be created) to meet the opportunities emerging from climate change and (2) the sustainability and generic competencies required of employees in these positions and industries. Interviews were also conducted with policy makers in the Hong Kong, China's VET system to identify changes that have already been implemented or planned, and will identify what would be required in order to respond to industry needs, where changes would be required in future, and the barriers that would need to be overcome. Interview data were recorded, transcribed and coded thematically.

One-on-one interviews were conducted with representatives of both carbonvulnerable industries and industries for which carbon constraints present possible economic opportunities, as identified through analysis of industry statistics and reports. Interviewees included representatives of the electricity generation, transport, construction contracting, engineering, textile, tourism, hospitality and beauty training sectors. Interviews were also conducted with representatives of NGOs.

The Vocational Training Council (VTC) of Hong Kong, China's through its corporate environmental office distributed a five-question survey to its 18 internal training boards, which encompass accountancy, automobiles, banking and finance, industry, building and civil engineering, IT training and development, management and supervisory training, technologist training, electrical and mechanical services, electronics and telecommunications, import/export/wholesale trades, mass communications, metal working, plastics, printing and publishing, retail trade, security services, textile and clothing and transport logistics.

The interviews were conducted in a semi-structured fashion. Experience suggests that business representatives can display differing reactions when asked about environmental initiatives, ranging from a very positive response and willingness to talk to an almost apologetic response when an interviewee does not realise that initiatives have been taken. In the latter case, it is necessary to draw out the desired information carefully to prevent the interviewee from becoming uncooperative. Four broad discussion topics were used, with the intention of conducting the interviews as conversations.

Under the theme of Targets and Policy, general questions were posed to solicit the interviewee's views and attitudes regarding the feasibility of the government's energy and carbon emission reduction targets in the context of his or her employment sector. The questions within Initiatives and Plans asked about business 
practices, plans and views concerning energy saving initiatives and carbon emission reductions. Those under the theme of Fundamental Changes asked the interviewees to consider future developments within their sector and to give their opinion as to whether there would be fundamental changes in their business and in attitudes towards these changes in the context of the low-carbon green economy. Finally, Workforce Skills included questions designed to elicit interviewees' views on skills needed in the workforce and changing training needs in the near and longer term.

During the discussions arising from these four areas, the interviewer sought to elicit information on whether the interviewees' businesses employed workers with vocational skills, the types of qualifications they needed, their in-house training provision, the skills that TVET facilities should provide now or in the short term and the skills that they will need to provide in the medium to long term.

The five questions that the VTC posed to its internal training boards were related to the inclusion of trade-specific environmental study elements and the percentage of environment-related content in VTC higher diploma (HD) and Diploma of Vocational Studies (DVS) courses for different industries/sectors.

\section{Employer Responses to the Issue of Carbon Constraints}

\section{Electricity-Generating Sector}

One representative of the electricity-generating sector explained that the government's target of a $25 \%$ energy reduction by 2030 could be achieved. For example, fuel consumption could be reduced by $1 \%$ per year through more energyefficient practices. Electric vehicles had been in use since the 1980s, and 10 new such vehicles were purchased by the electricity-generating company in 2010. Hong Kong Island had charging infrastructure that could be used at no cost until the end of 2011. The ratio of gas-fired electricity generation had risen to $33 \%$ of the total by 2010, with the Lamma Power Station achieving a $13 \%$ reduction in $\mathrm{CO}_{2}$ emissions. The electricity-generating sector wanted to see collective effort from all parts of the community to promote energy conservation through energy efficiency-related services and public education, the representative stated, and it supports further research into more cost-effective renewable energy production.

In response to questions on the environmental initiatives introduced, the electricity-generating industry representative advised that in 2008 the industry successfully reduced its carbon footprint and complied with the revisions of the Hong Kong Business Guide to Emission Reduction published by the Climate Change Business Forum. The representative's company was committed to the Carbon Reduction Charter initiated by the Government of the Hong Kong Special Administrative Region of the People's Republic of China in 2008, and carbon audits had been conducted for corporate buildings, electricity installations and selected buildings at the Lamma Power Station. In 2009-2010, the company 
achieved a 13\% reduction in its carbon footprint by reducing electricity and paper consumption and water and vehicle fuel use between 2007 and 2009.

The electricity-generating sector promoted energy efficiency and conservation through the provision of advisory services to residential and commercial customers and support for public education. Since 1999, for example, the representative's company had offered more than 1,000 professional energy audits and energy saving solutions, helping business customers to achieve average energy savings of 5\%-20\%. It also launched a GREENPLUS programme to bring together different parties, including government departments, an energy advisory committee, professional bodies and academics to exchange ideas and technical expertise on the development and implementation of environmentally friendly solutions. At the community and corporate level, the there were efforts to encourage behavioural changes, and programmes were provided to promote energy efficiency. For example, the Go-Green programme had promoted a green office culture since 2005 and helped to reduce electricity consumption in Hong Kong, China offices by 9\% between 2005 and 2009. Building energy codes had also been implemented, in addition to such energy conservation measures as green roofs, vertical greening and smaller window areas.

When asked about the fundamental changes to the electricity-generating industry and individual businesses in a carbon-constrained economy, the representative suggested that such changes could be both risks and opportunities. In relation to promoting electric vehicles, the representative mentioned that the company had introduced quick charging equipment and advocated a building efficiency code to ensure that its infrastructure and transmission work was environmentally friendly and energy efficient.

Another electricity-generating industry representative recognised that the power industry generated two-thirds of Hong Kong, China's $\mathrm{CO}_{2}$ emissions and thus plays an important role in reducing carbon intensity. When asked about the industry's short- and long-term TVET needs, this representative emphasised the need for staff to be environmentally aware, to care about environmental protection and to have diverse disciplinary backgrounds, such as the social and environmental sciences.

The representative stated that the company employed craftsmen and technician trainees undertaking VTC training programmes. More diverse training would encompass chemical, mechanical, civil and environmental engineering, and new skills for engineers would include energy and carbon audit skills.

A third representative of the electricity-generating industry emphasised that staff needed to keep up with technical developments and new technology in the power industry to support the development of sustainable energy businesses and energy efficiency and conservation initiatives. The representative predicted that the increased use of clean energy would make necessary staff capability in related technical areas, although existing skill sets and technical capabilities would remain important in the near to medium term.

This representative also predicted that high-carbon industries and associated skills would gradually disappear, particularly in developed economies such as Hong Kong, China. Skills related to carbon-intense coal-fired generation and internal combustion engines would be gradually replaced by clean/green generation 
technologies such as electric vehicles. The representative talked about the training scheme provided by the Hong Kong Institution of Engineers (HKIE). This was a credit-based scheme in which graduate trainees receive training in mechanical, electronic/electrical, environmental and civil engineering.

\section{Transport Sector}

The transport industry was represented in the interviews by representatives of a rail operator, an airline and an airport operator. As the rail sector had already achieved a $19 \%$ reduction in energy use, the rail operator representative advised that it would be very difficult to achieve a further $25 \%$ reduction because of the high cost of replacing facilities to improve energy efficiency. However, the transport industry (including the bus companies) was very proactive in energy reduction. The representative commented that the $25 \%$ energy reduction target and proposed change in the fuel mix for electricity generation was 'aggressive but achievable'. The rail operator monitors contractors' use of materials and energy, such as concrete, steel, fuel and electricity, according to its 2010 annual report.

The airline representative described the $25 \%$ energy reduction target as 'ambitious but doable'. For ground emissions, $25 \%$ was considered realistic. However, for airlines most emissions are from aircraft. ${ }^{1}$ Other sources of energy use were miscellaneous vehicles and equipment and office buildings. Energy-efficient equipment had also been installed, with a 10- to 20-year cost recovery period, and buildings were constructed in accordance with Hong Kong China's energy-efficient building code. The airline had approximately 750 suppliers and covered 150 destinations. It exercised strict control over such suppliers as catering services and laundry and other subsidiary companies, which have a great impact on carbon emissions and water use.

The airport operator's representative expressed a commitment to reducing carbon emissions by influencing suppliers and contractors and imparting information and education through lectures to suppliers and other organisations. The energy reduction target of $25 \%$ by 2030 was considered tough but realistic. The focus was on 'energy efficiency', such as replacing traditional lighting with light-emitting diodes (LEDs) and implementing more efficient temperature controls. Contractors were encouraged to replace existing vehicles with electric vehicles, but there was no way to enforce this.

The rail operator representative stated that the railway and property sectors were reducing their energy use. There had been a variety of initiatives, ranging from stopping escalators during off-peak periods to the use of LEDs in trains, stations and platforms, installation of platform screen doors and optimisation of building management systems in both transit facilities and properties. The sector's major

\footnotetext{
${ }^{1}$ Aircraft emissions are not currently counted as part of Hong Kong, China's carbon footprint.
} 
initiative was computer-controlled train management for optimised energy use. The operator used lighter trains, which were more energy efficient, and had installed energy-efficient lighting.

The airline representative discussed the 'four pillars' of airline operations, which the International Air Transport Association (IATA) defines as the modernisation of fleets with more fuel-efficient aircraft to reduce $\mathrm{CO}_{2}$ emissions, the adoption of operational procedures that make use of the most fuel-efficient routes, the use of an efficient infrastructure to reduce additional weight on flights; and the employment of economic instruments to reduce carbon emissions. On the ground, the airline had established one of the largest electrical vehicle fleets in Hong Kong, China, numbering more than 100 electric vehicles. In the airline's buildings, solar heaters were used and energy for lighting was generated by a wind turbine. The airline planned to further reduce electricity consumption through the use of more advanced controls, such as more energy-efficient flight simulation equipment during training sessions. The Fly Greener campaign was initiated to encourage passengers to pay for carbon offsets.

The airport operator representative discussed the environmental measures that have been adopted since the airport's construction. In 2008, the Government of the Hong Kong Special Administrative Region of the People's Republic of China published carbon audit guidelines, on the basis of which the operator undertook its first carbon audit. In 2009, it extended the audit to the entire airport, including terminal buildings, office towers, airlines, ground service contractors, equipment companies, government departments and catering companies. Around 40 companies took part in this audit, the results of which indicated that electricity accounted for $70 \%$ of the airport's carbon emissions, with ground services and cargo accounting for another $10 \%$ each. The 40 companies involved developed carbon reduction plans based on these results, later publicising them online, quite a novel exercise in Hong Kong, China.

The transportation industry representative thought that the industry would react to what the customer wanted. There was a perception that transportation designed for low-carbon emissions was more expensive. The representative recommended that detailed studies be undertaken to streamline the connections amongst different modes of transport.

The airline representative described the aviation industry as a growing sector and noted that sustainability posed a considerable challenge that required the examination of everything from food to seat fabric. Carbon reduction was the most challenging issue, and this would fundamentally change the way the industry worked. The representative recognised that reducing carbon emission also reduced operational costs. Finding a way to survive without government subsidies while meeting customer expectations and reducing its environmental impact would represent a major challenge for the industry.

The airport operator's representative stated that the operator intended to electrify its ground service equipment to reduce carbon emissions and improve air quality. 
In light of increasing concerns about climate change in the aviation industry, the operator had to consider the environment and sustainability in its further development, such as in plans to expand the number of runways and make greater use of renewable energy. The representative said that energy-efficient buildings would be constructed as a part of airport expansion. Staff at the Airport Authority had developed a sense of responsibility for the environment.

The rail operator representative reported that the industry was concerned about lifecycle and cost-benefit assessments and providing solutions to mobility issues using BATNEEC (which stands for 'best available technologies not entailing excessive cost'). The rail company still required university-educated staff with the capability to understand such concepts as global reporting indicators and environmental cost-benefit analysis. It was suggested that vocationally trained workers needed skills to work with ventilation and heat-insulation systems, electrical work and the installation and repair of energy-efficient building materials.

The airline operator considered that it was difficult to find people with environmental or engineering background and skills as well as understanding of business, policy and aviation regulations. Environmental communication skills were required for environmental specialists in the aviation industry for PR purposes. Environmental business skills such as knowledge of carbon auditing and reporting were considered necessary.

The airport operator organised training sessions for its business partners and airport staff, for example, to demonstrate the benefits to the airport (and hence the community) of electric vehicles compared to conventionally powered vehicles. Special training is required for the maintenance of electric vehicles, which is currently provided only by the equipment suppliers.

The rail operator provided in-house training for employees. Retraining on environmental and sustainability issues was also provided to ensure that staff understood how to report such issues with transparency. Training was also provided in lifecycle assessment, reporting and learning through experience. Attendance at evening classes, seminars and courses was encouraged.

The airline operator encouraged training but did not make it mandatory. Junior staff were encouraged to take courses in carbon auditing and environmental management systems (EMS). Briefings were provided for senior staff, but no formal training. Although the operator conducted no in-house training, it employed external trainers from, for example, the University of Hong Kong and Corporate Social Responsibility Asia, to teach courses on environmental standards and environmental auditing, monitoring and reporting. E-learning courses on environmental issues were also available to employees at no cost. The representative emphasised that no training on emission trading schemes was available locally, and that experiencebased on-the-job training would be helpful.

Finally, the airport operator held briefing sessions for senior management on the issues of carbon constraints and carbon auditing. It also provided training and workshops free of charge to external organisations working at the airport as part of its commitment to influencing business partners. 


\section{Construction Sector}

The construction industry representative indicated that contractors were not particularly active in implementing changes in their working methods to effect carbon reduction, and that any changes that did take place were either for cost savings or in response to changes in the law or government guidelines. The representative stated that construction waste disposal charges had been implemented in recent years and that more stringent disposal criteria are encouraging the reuse of materials on-site. Furthermore, recycled materials were gaining in popularity, and clients, engineers and contractors were much more open-minded about and amenable to suggestions for the use of these materials.

This representative noted that changes in the construction industry occurred very slowly and it was unlikely that any radical or fundamental changes would occur. Although building design was gradually changing in line with the principles of the building environmental assessment method (BEAM), that did not involve radical changes. The construction industry representative further stated that workers in the sector did not need special training in the use of new materials because they always came with detailed instructions for handling and use. This demonstrated the power of market forces because products that were not easy to work with or needed special skills would not be selected.

Finally, the representative reported that environmental staff were required to take the training courses provided by the Construction Industry Council. The EPD also provided information on environmental laws and guidelines, he said, and there is input from industry practitioners and construction contractors. On-site environmental staff then provided information to workers on good site practices for preventing nuisance (noise, dust, silty run-off, vehicle cleaning and stockpiling). In addition, environmental good practice extended to office procedures, such as switching off lights and air conditioners in unused offices. The aim was to make environmental issues a matter of routine.

\section{Property Sector}

The property industry representative considered the government targets to be challenging but achievable in light of available technology and political and economic concerns. However, the use of renewable energy may not produce positive environmental benefits if carbon emissions from production are taken into account. Solar power for the provision of hot water was one practical measure that could be introduced.

This representative further noted that high-efficiency lighting systems, such as LED lighting, and air-conditioning systems had gained popularity in recent years. Knowledge-based energy management that focuses on the use and analysis of operating data to optimise heating, ventilation and air-conditioning systems were 
also achieving energy savings. The challenges facing the property industry included identifying well-trained technical staff who can make a good business case for energy efficiency initiatives to senior management, convincing decision-makers that value should be placed on reducing carbon emissions, adopting new technology and the government's carrot-and-stick approach, which involves grants for the implementation of energy efficiency coupled with economic instruments to discourage waste. It was also emphasised that the mandatory building energy code was driving the industry to prepare for and carry out energy audits.

The property industry representative argued that businesses with less dependence on energy or those that transferred the cost down the supply chain would be most proactive in seeking opportunities in the low-carbon economy and could benefit most from a carbon-constrained future, in the property industry representative's view. In this context, fundamental changes could occur in regulations, public demand, carbon costs and the availability of information to increase awareness of technological advances. The representative pointed out that businesses that managed the risks of a low-carbon economy would see it as an opportunity rather than something to be feared, and that this could be used to improve competitiveness, profit and company image.

This representative also emphasised the importance of adapting energy management technology knowledge acquired in universities to the commercial environment and of getting information across to non-technical decision-makers. A commitment to environmental issues at the management level was needed to drive the industry and influence government.

\section{Tourism Sector}

The tourism industry representative highlighted the sector's commitment to promoting Hong Kong, China's diversified tourism appeal while supporting environmental protection measures, such as the development of ecotourism facilities for green tourism, nature conservation and education. Examples include the Hong Kong Wetland Park and Hong Kong National Geopark. The representative was enhancing staff environmental awareness and knowledge by setting up electronic operating procedures and displaying posters with environmental messages in the office.

\section{Employers' Responses to Opportunities Provided by Carbon Constraints}

\section{NGO Sector}

The nongovernmental organisation (NGO) representative advised that it was an NGO's job to work with businesses to achieve government targets for carbon 
reduction and energy savings, noting that $85 \%$ of current emissions came from electricity generation. Government policy was for the use of coal to be phased out by 2030 , which put pressure on the electricity-generating companies to adapt. However, the phasing out of coal provided opportunities for the consideration of alternative means of energy generation.

The NGO representative also pointed out that the shipping and aviation industries accounted for a large proportion of emissions in Hong Kong, China. There was pressure to encourage container ship operators to change to low sulphur fuel $(<0.5 \%)$ when they came into port in Hong Kong, China and a number had already agreed to do so. At the individual consumer level, there was a responsibility to buy organic food and/or sustainably produced goods, even though they may be more expensive. Other individual initiatives to reduce emissions included reductions in travel, the consumption of less meat and the purchase of locally produced goods. The NGO representative also described an initiative to establish a Building Efficiency Fund to allocate funds for carbon audits and building upgrades. The NGO was identifying the path by which to move Hong Kong, China towards a low-carbon economy through appropriate investments, generating ideas, demonstrating good corporate behaviour and working with government.

\section{Engineering Sector}

The engineering industry representative considered the government target to be definitely achievable by 2030 and cited the example of one contractor that was active in energy reduction through such means as painting site offices with reflective paint to reduce the use of air conditioners. This had the advantage of saving money and being environmentally sustainable. It also required no special skills or technology. A sustainable construction framework was being developed, although that was challenging as it required changes not only in procedures but also in mindset.

The industry had been working hard on the sustainability issue in the last 10 years to enhance performance and reduce costs in a holistic way. Information was being collected in Australia and the Asia-Pacific as well as from company offices in the region to identify their carbon footprints. The company's new Hong Kong, China head office building was designed in-house with energy efficiency as a key design element.

Furthermore, carbon footprint planning was being developed for personal and business travel, and requests for sustainability strategies are being received from clients. For example, the company had received requests for the design of ecofriendly cities and sustainability assessments for cycle tracks, bridges and highways, and the English Schools Foundation had commissioned it to carry out carbon audits of day-to-day school operations. The company had also established a network that brought together people from different divisions to showcase projects. The interviewee reported that the company had achieved a $5 \%$ year-on-year overall reduction in energy consumption across its different operations, which had also reduced carbon emissions and costs. 


\section{Textile Sector}

The textile industry representative commented that the government's reduction targets were achievable, as many companies and factories wasted energy. The company had implemented such measures as installing energy-efficient lighting and using air conditioning sensibly to help to reduce energy consumption. The representative also cited examples of new dyeing procedures, such as those that do not require boiling water, which are more energy efficient. Energy-efficient machinery was now available. One buyer even required the company, as a supplier, to measure its carbon footprint as part of the buyer's environmental reporting requirements.

\section{Hospitality Sector}

A food and beverage manager from the hospitality industry expressed concern over the difficulty of implementing energy-saving measures, as it was necessary to provide clients with what they need. For example, it would not be possible to close the kitchens or certain areas of the club for parts of the day, unless this was actually requested by the members. However, the representative did acknowledge that environmentally friendly lighting and more energy-efficient equipment could be installed when the club was due for renovation. The club provided a large amount of imported bottled water, but, again, this was in response to member demand and not amenable to change. The manager noted that kitchen staff were aware of the need to reduce costs, and as a result, food wastage was minimised through careful and flexible menu planning. This was an area in which vocational training could have a positive impact. Catering students could be trained to consider food costs and be taught techniques for minimising food wastage.

The manager said that the club has discussed an initiative to buy organic vegetables, but doing so depended on costs. The club promoted organic foods and supported the organic farm run by the government through the promotion of its produce. For operational reasons, there was a preference for labour-saving products such as packaged organic milk, which also sold well.

\section{Therapy Sector}

The therapy industry representative indicated that energy conservation was not a priority. This was a relatively new business sector and it had not yet developed a sense of environmental awareness, although in future energy saving concepts such as the use of more energy-efficient equipment could be incorporated into training courses. The representative noted that European products were more environmentally 
friendly and could be used to a greater extent. Over the long term, less equipment could be used for treatments that could also be provided by hand. The representative considered it important to develop an industry standard for protecting the environment.

\section{Employers' Perspectives on Vocational Training for Green Jobs}

The NGO representative indicated that new jobs were emerging in carbon auditing and design and that skills upgrades are required for such jobs as facilities maintenance. Although it could be clearly seen that such industries as construction have opportunities to become more sustainable, change was also possible in less obvious occupations such as accountancy, which could, for example, include carbon auditing or trading in the services they provide. Jobs in teaching, retail, packaging, stock management and the carbon labelling of goods could also change, and office managers would need to be aware of paper sourcing and usage and know how to recycle efficiently. Building mangers also required training in energy efficiency. The representative noted that 900 carbon auditors, filling a new green position, had been trained in Hong Kong, China in the last 2 years. There were also many sustainability managers and directors of operations with embedded green skills.

The NGO representative highlighted the shortage of skills in carbon auditing and foot printing and noted that the building industry was lacking people with environmental or sustainability knowledge. BEAM training provided by the Hong Kong Green Building Council had resulted in hundreds more BEAM assessors than there were just a few years ago. Those working in restaurants or commercial buildings also required training in waste separation and recycling.

The engineering industry representative considered the key differentiator amongst engineering companies was how cost analysis tools were used for sustainability assessments for new infrastructure development. Within the representative's company, it had become standard practice to advise on sustainable strategies as part of the design process.

In terms of training, the representative emphasised the importance of such basics as understanding chemistry, water engineering and the treatment of wastewater and clean water. Existing training relied heavily on computer modelling with no understanding of fundamentals or basic principles, and there was a preference for in-house training. Although the representative suggested that graduates should have more knowledge and awareness of environmental issues, graduate architects and engineers did have a better understanding of these issues than they did in the past. The representative had experienced the need to adapt to green issues and sustainability, starting out as a water engineer, moving into environmental and sustainability consultancy and finally being concerned with the specific requirements of adaptation to a carbon-constrained future, all within the same company. 
The textile industry representative emphasised the need for workers to be trained in the use of energy saving machinery to achieve optimal functional ability. Skills could still be applied in the textile technology even if the machinery was changing.

According to the representative, the textile industry required specialised pre-job training in addition to on-the-job training. The curricula of relevant courses did not incorporate green concepts. However, the representative emphasised the importance of reducing the use of energy and chemicals and recommended management courses that advise offices and factories of possible ways to reduce energy use. In future, there would be a need for people to oversee energy consumption in the office and in operations. In addition to vocational training, company guidelines needed to be developed to apply corporate responsibility to the environment.

The hospitality sector representative highlighted the importance of controlling wastage in food preparation to save costs. A good chef, in addition to cooking, needed to manage the kitchen, which included responsibility for food costs. General education was cited as the arena for promoting individual environmental awareness and responsibility.

The aesthetic therapy industry representative mentioned the importance of having a diploma, certificate or other qualification. 'Skills must be renewed at the same time', the representative said, describing a beautician's skills as a 'handicraft'. Vocational training should incorporate green and environmental concepts into the curriculum.

The PR representative stated that 'as telecommunications and computerised technology will dominate the whole world's development, PR practitioners need to improve their skills in communication networks and computerised know-how in future'.

The vast majority of respondents to the VTC survey considered it necessary or relevant to include trade-specific environmental study elements in the VTC's HD courses. Only one person disagreed. With regard to the suitable amount of tradespecific environmental content for any course, responses ranged from $5 \%$ to $30 \%$. The respondents suggested that such content should cover such subjects as corporate and social responsibility for the environment, environmental management accounting and environmental management, policy and regulations.

\section{Conclusion}

What came across strongly in the interviews was that current efforts to reduce firms' carbon footprint are focused largely on energy reduction and waste minimisation, which may stem from a 'business-as-usual' approach that makes a few concessions to sustainability through the use of energy-saving technologies. There is little to be seen that is radical, with the arguable exception of the engineering sector in which designers, who are not specifically trained in environmental management, are actively designing buildings to maximise energy efficiency and using these designs as a selling point. The engineering industry 
appears to have experienced a change in mindset. Ten years ago, environmental work was largely concerned with impact assessment to secure environmental permits for projects or to obtain planning permission, but sustainability is now considered a major factor in building and civil engineering design.

The transport industry appears to have strong potential for energy reduction, although investment in vehicles (planes, trains and buses) has locked operators into specific technologies for the lifespan of the vehicle, which, in the case of planes and trains, could be $20-40$ years. The process of technological improvement therefore progresses over a longer time frame. Transport in Hong Kong, China is commercially oriented, and there is little incentive at the operational level to discourage travel as a means of carbon reduction. The government could force travel restrictions through the introduction of economic instruments, but doing so would most likely be deeply unpopular.

Commercial considerations were also the major concern for the service industry, in which stiff competition demands that firms provide what customers want. Change is likely only in response to government regulations or customer pressure. Minimising waste is the main means of carbon footprint reduction at present.

In terms of vocational training, it appears that very few employees enter the workforce with useful 'green skills'. In general, the businesses and other organisations surveyed provided in-house training or arrange external courses. There appears to be a lack of green skills provision through the current vocational training system, although in theory $5 \%$ of the content of vocational courses is supposed to relate to sustainability issues. This issue was not of particular concern to most of the interviewees, as there were few genuine 'green jobs' available, and green skills can be taught on the job with reference to particular business requirements. However, the NGO business advisor made the interesting comment that rather than consider which jobs will incorporate an element of sustainability and green skills in future, it would be better to consider which jobs will not.

Open Access This chapter is distributed under the terms of the Creative Commons Attribution Non-commercial License which permits any non-commercial use, distribution, and reproduction in any medium, provided the original author(s) and source are credited.

\section{References}

Chan, B. (2009, November 18). Private discussion with the principal of a vocational education institute. (Unpublished personal communication).

Climate Change Business Forum. (2009). Retrieved November 13, 2009, from http://www. climatechangebusinessforum.com/en-us/ghg

Environment Bureau/HKSAR Government [of the People's Republic of China]. (2010). Hong Kong, China's climate change strategy and action agenda consultation document. Retrieved June 8, 2012, from http://www.gov.hk/en/theme/bf/consultation/archives_2010.htm

Fien, J., Maclean, R., \& Park, M. (Eds.). (2008). Work, learning and sustainable development. Dordrecht: Springer. 
Hung, H. (1998). A study of the decision making bodies of the Vocational Training Council in Hong Kong, China. Journal of Vocational Education and Training, 50(1), 41-59.

IPCC. (2007). Climate change 2007: The physical science basis, contribution of working group I to the fourth assessment report of the Intergovernmental Panel on Climate Change. Cambridge: Cambridge University Press.

Martinez-Fernandez, C., Hinojosa, C., \& Miranda, G. (2010). Green jobs and skills: the local labour market implications of addressing climate change (Working document, CFE/LEED). Paris: OECD. Retrieved June 8, 2012, from www.oecd.org/dataoecd/54/43/44683169.pdf? contentId $=44683170$

Stern, N. (2009). A blueprint for a safer planet: How to manage climate change and create a new era of progress and prosperity. London: Bodley Head.

The Climate Group. (2008). What is the Leadership Role for Hong Kong, China in Carbon Trading? Hong Kong, China Climate Change E-Bulletin, (3), 1-2

Tsang, D. (2010). The 2010-11 policy address sharing prosperity for a caring society. Retrieved June 8, 2012, from http://www.policyaddress.gov.hk/10-11/eng/index.html 